\title{
Treatment of Dogs With Oral Melanoma Recurrence by Diode Laser Excision
}

\author{
Cornel IGNA ${ }^{1}$, Daniel BUMB ${ }^{1}$, Bogdan Sicoe ${ }^{1 *}$, Roxana DASCALU ${ }^{1}$, Larisa SCHUSZLER ${ }^{1}$ \\ ${ }^{1}$ Banat's University of Agricultural Science and Veterinary Medicine, "King Michael I of Romania" from \\ Timisoara, Romania \\ *corresponding author: bogdan.sicoe@yahoo.com
}

Bulletin UASVM Veterinary Medicine 73(2) / 2016,

Print ISSN 1843-5270; Electronic ISSN 1843-5378

DOI:10.15835/buasvmcn-vm: 12072

\begin{abstract}
Treatment of oral melanomas utilizes the surgical excision-resection (Culp et al., 2013) and/or radiation therapy (Proulx et al., 2003), chemotherapy with carboplatin (Brockley et al., 2013), immunotherapy (Ottnod et al., 2013). Treatment based on surgical excision is usually palliative (Freeman et al., 2003). In the literature even though there are data concerning the prognosis of oral melanomas in dogs after surgery, are missing data after laser excision. Taking into account these findings we wished to present our experience regarding three cases of oral melanoma recurrence and immediate and long term laser surgery results.

The casuistry consisted of three dogs with recurrent oral malignant melanomas, subjected to surgical reintervention. The initial diagnosis was melanotic melanoma in stage I or II. The animals were brought back at different time intervals from originally excision with electric scalpel. Before reintervention, dogs were subjected to clinical, paraclinical exam and biopsy. Excision of the tumor mass was made with an optical fiber hawing a diameter of $400 \mu \mathrm{m}$, at a power of $10 \mathrm{~W}$ and a wavelength of $940 \mathrm{~nm}$ with a diode laser. At 1, 2, 3, 6 and 12 months after laser reintervention the dogs were reexamined. Average time in which appeared canine oral melanoma relapse was 58.6 days. After reexamination all cases where reinstatement in stage I. Operators times were held in conditions of comfort with wide access, minimum bleeding, and effective hemostasis. After surgery at 24 hours on the intervention place a slight local redness, without swelling and bleeding was observed. Palpation revealed initially also a slight local sensitivity which completely disappeared in 48 hours. There were no grasping and chewing disturbances. Macroscopic healing occurred in 7-9 days. At last recheck performed at 12 months there were no evidences of tumor recurrence or metastasis. Diode laser excision of oral malignant melanoma in dogs can be an alternative palliative procedure to invasive surgical resection procedures. The average of free recurrence and metastasis time after laser surgery has exceeded 360 days in these three cases.
\end{abstract}

Keywords: canine oral melanoma, diode laser

\section{INTRODUCTION}

Melanoma with oral location is a common malignant neoplasm in dogs, affecting mostly older animals (Bostock, 1979; Gilard et al., 2014; Nishiya et al., 2016; Ogilvie and Moore, 1988; Ramos et al., 2000; Thomas and Fox, 1998). Canine oral melanoma represents between 14.4 and $45.5 \%$ of oral tumors (Nishiya et al., 2016; Todoroff and Brodey, 1979). The breeds most commonly affected are: Poodle, Dachshund, terriers and Golden Retriever, Chow Chow, Boxer, Rottweiler (Gilard et al., 2014; Modiano et al., 1999; Ogilvie and Moore, 1988).

Canine melanomas are classified into two types: melanotic and amelanotic, based on terms of clinical behavior, cells' multiplication and connexin expression (Teixeira et al., 2014). The 
amelanotic variant is very aggressive (Teixeira et al., 2014).

Treatment of oral melanomas utilizes the surgical excision-resection (Bradley et al., 1984; Culp et al., 2013; Felizzola et al., 2002; Kosovsky et al., 1991; Wallace et al., 1992) and/or radiation therapy (Proulx et al., 2003; Freeman et al., 2003), chemotherapy with carboplatin (Brockley et al., 2013; Freeman et al., 2003), immunotherapy vaccines with dendritic cells (Grosenbaugh et al., 2011; Ottnod et al., 2013).

The indicated treatment is based on extensive surgical resection - hemi mandibulectomy or maxillectomy (Bradley et al., 1984; Felizzola et al., 2002; Kosovsky et al., 1991; Wallace et al., 1992). Treatment based on surgical excision is usually palliative (Culp et al., 2013; Freeman et al., 2003) with few studies reporting a curative action, canine oral melanoma having a high rate of relapse - 3-28\% (Culp et al., 2013; Esplin, 2008; Tuohy et al., 2014) and development of metastasis. The rate of metastasis of oral melanoma in dogs is between 14 and 92\% (Nishiya et al., 2016; Ramos et al., 2000; Williams and Packer, 2003), with an average of about 80\% (Thomas and Fox, 1998). The median survival time post-surgery (classical surgery) in dogs with oral melanoma is 147-241 days (Brockley et al., 2013; Culp et al., 2013).

In the literature even though there are data concerning the prognosis of oral melanomas in dogs after surgery (Bostok-1979; Esplin, 2008; Hahn et al., 1994; Harvey et al., 1981; MacEwen et al., 1986; Smedley et al. 2011; Tuohy et al., 2014), data on the prognosis after laser excision are missing.
In this case report are presented data recorded by laser excision of oral malignant melanoma in dogs.

\section{MATERIALS AND METHODS}

The casuistry included in this study - table 1 , consisted of three dogs with recurrent oral malignant melanomas, subjected to surgical reintervention by laser excision of the tumor masses.

The initial diagnosis was established by clinical, radiographic and histological exam, in all three cases being melanotic melanoma in stage I or II, according to TNM classification (tumor, lymph node, metastasis) of the World Health Organization for oropharyngeal tumors (Bergman 2007; Freeman et al., 2013), T - tumor $\mathrm{cm}$ in diameter, a-b - mitotic index no/field 1-2 location (1- rostral mandible/caudal maxilla; 2 another), $\mathrm{N}$ - lymph nodes involvement, $\mathrm{M}$ - distant metastases). The animals were presented again in the Surgery Clinic of FMV Timisoara at different time intervals (table 1) from classical surgical intervention performed originally (excision with electric scalpel).

The time interval without relapse was calculated between the time of the first surgery and time of the owner presentation to signal the relapse observed macroscopically. Decision for surgical reintervention was taken after owners' refusal to accept an invasive surgical procedure (mandibulectomy or maxillectomy).

Before surgical reintervention, the dogs were subjected to clinical and paraclinical exam (complete physical examination, thorough oral

Tab.1. Casuistry of relapsed canine malignant melanoma

\begin{tabular}{|c|c|c|c|c|c|c|}
\hline No & Breed & $\begin{array}{c}\text { Age } \\
\text { years }\end{array}$ & $\begin{array}{c}\text { Weight } \\
\text { kgs }\end{array}$ & Sex & The initial diagnosis & $\begin{array}{c}\text { Time interval after } \\
\text { which the relapse } \\
\text { has occured } \\
\text { days } \\
\end{array}$ \\
\hline 1 & Poodle & 12 & 9 & M & $\begin{array}{l}\text { Palatal melanoma with rostral } \\
\text { location } \\
\text { stage I - } \mathrm{T}_{1} \mathrm{a}^{2}, \mathrm{~N}_{0}, \mathrm{M}_{0}\end{array}$ & 36 \\
\hline 2 & Rottweiler & 9 & 36 & M & $\begin{array}{c}\text { Gingival right jaw melanoma with } \\
\text { caudal location } \\
\text { stage II }-\mathrm{T}_{2} \mathrm{a}^{1}, \mathrm{~N}_{0}, \mathrm{M}_{0}\end{array}$ & 95 \\
\hline 3 & $\begin{array}{l}\text { German } \\
\text { Shepherd }\end{array}$ & 12 & 32 & $\mathrm{~F}$ & $\begin{array}{c}\text { Gingival maxilla melanoma with } \\
\text { rostral location } \\
\text { stage II }-\mathrm{T}_{2} \mathrm{a}^{1}, \mathrm{~N}_{0}, \mathrm{M}_{0}\end{array}$ & 45 \\
\hline
\end{tabular}


examination, palpation of peripheral lymph nodes, chest radiography, complete blood count and blood biochemical analysis). Clinical examination revealed no respiratory changes and no changes in volume of regional lymph nodes. The paraclinical exam and imaging investigations were unremarkable. From biopsy samples taken before surgery, fresh cytological specimens were made by tissue samples mark on glass microscope slides and were stained with Diff-Quick, confirming the relapse.

The protocol for general anaesthesia included premedication with diazepam $(0.4 \mathrm{mg} / \mathrm{kg}$ b.w., i.v.) and ketamine ( $5 \mathrm{mg} / \mathrm{kg}$ b.w., i.v.), followed by induction with propofol ( $3 \mathrm{mg} / \mathrm{kg}$ b.w., i.v.). After endotracheal intubation, general anaesthesia was maintained with izoflurane vaporized in oxygen using intermittent positive pressure ventilation. Postoperative analgesia was provided with

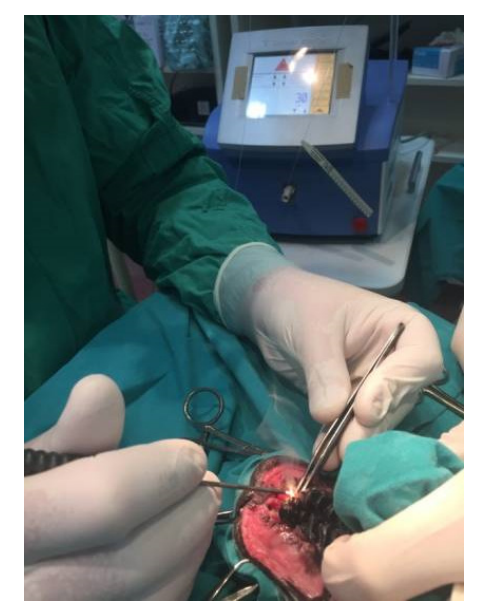

Fig. 1. Diode laser excision

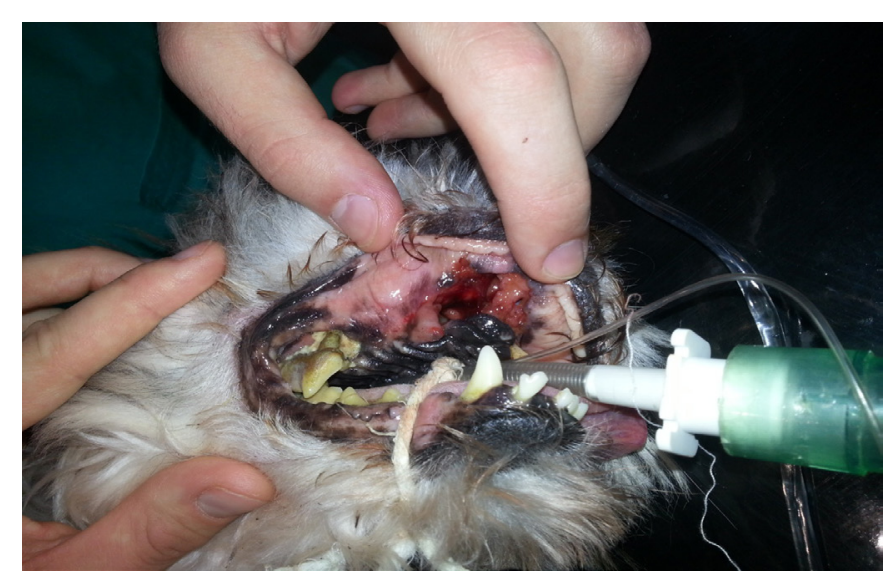

Fig. 3. Initial preoperative appearance one dose of butorphanol $(0.4 \mathrm{mg} / \mathrm{kg}$ b.w., s.c. $)$ administered within 15 minutes before recovery. Ampicillin (20 mg/kg b.w, i.v.) was administered at induction and at the end of surgery, which lasted two hours.

The dogs were placed in recumbency (dorsal or sterno-abdominal) with the neck in extension and mouth held open with a speculum.

Excision of the tumor mass was made with an optical fiber having a diameter of $400 \mu \mathrm{m}$, at a power of $10 \mathrm{~W}$ and a wavelength of $940 \mathrm{~nm}$ with a diode laser (Dornier Medilas D LiteBeam + Germany), in contact, working mode continuous wave - figure 1 . The device is equipped with Lightguide Protection System, thereby preventing the overheat of local tissue and damage of the optical fiber. Oral mucosa and submucosal incision was performed in presumed healthy tissue at a distance of 1-2 $\mathrm{cm}$ from the tumor mass. After excision, the oral

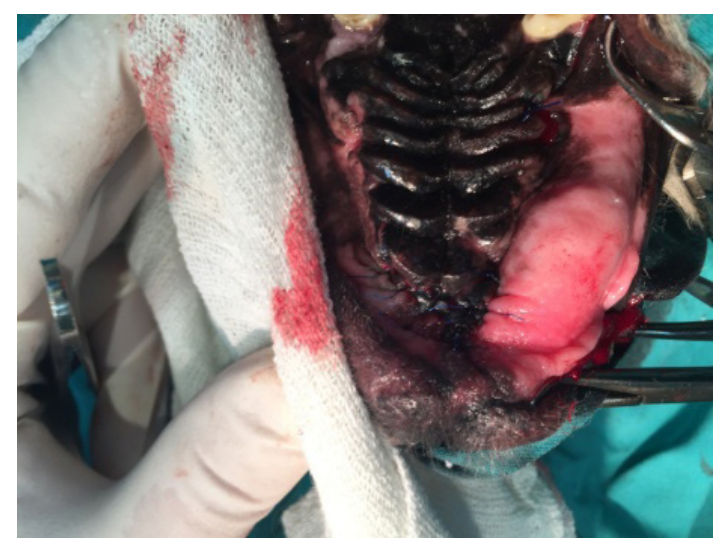

Fig. 2. Oral mucosa apposed in a simple interrupted sutures

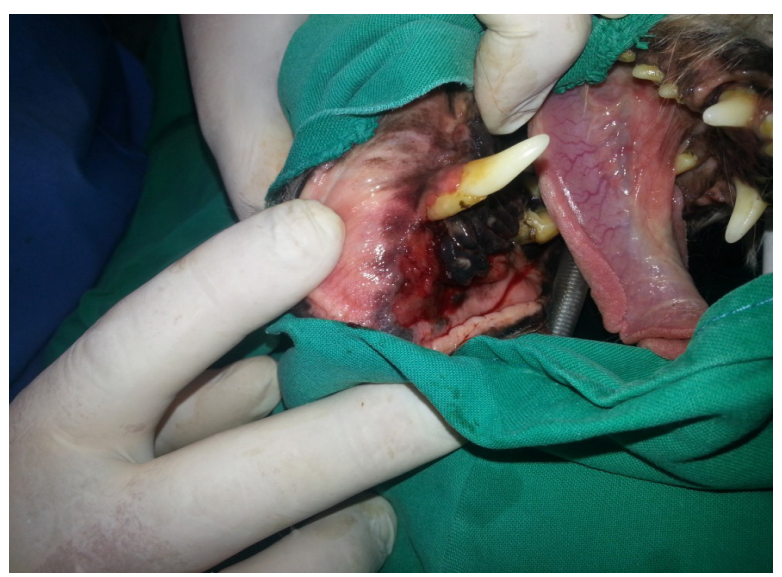

Fig. 4. Appearance of the relapse 


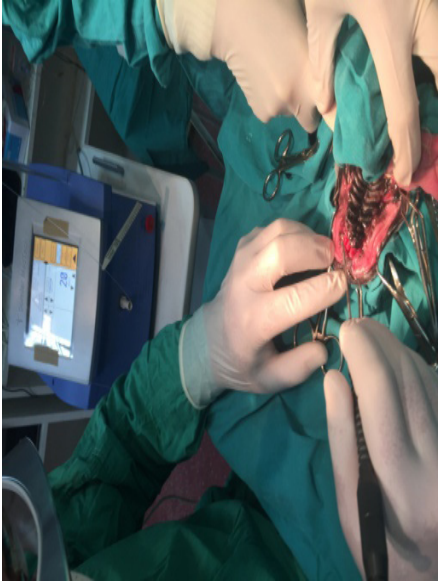

Fig. 5. Intraoperative appearance laser surgery

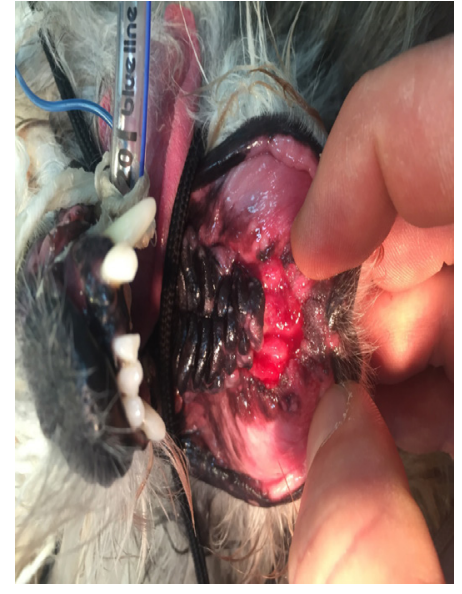

Fig. 6. Intraoperative appearance of intervention place

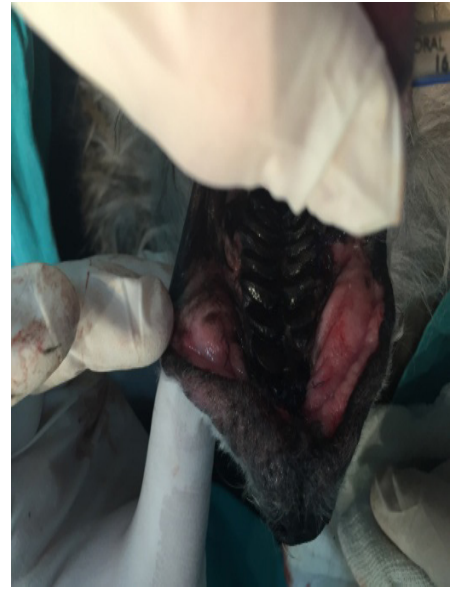

Fig. 7. At seven days mucosa was sutured in simple interrupted sutures using PDS II (2 metric) - figure 2.

Postoperatively, in the first 10 days, the animals were clinically examined daily observing: local pain on palpation, local swelling, presence of hemorrhage, the appearance of operative wound and speed of healing.

At 1, 2, 3, 6 and 12 months after laser reintervention, the dogs were clinically examined (complete physical examination, thorough oral examination, palpation of peripheral lymph nodes) and imagistically (thoracic - abdominal radiographs for evidence of metastasis).

\section{RESULTS AND DISCUSSION}

For the three cases included in this study (table 1) mean age was 11 years (range, 9-12 years) with an average body weight of $25.6 \mathrm{~kg}$ (range, 9-36 kg).

Average time in which canine oral melanoma has relapsed was 58.6 days (range, 36-95 days), ascertaining the halving of it, when compared to data from the literature (Freeman et al., 2013) which mentions a median time without recurrence of 139 days.

Compared to the initial stadialization (table 1 ), one case of malignant oral melanoma stage I $\left(\mathrm{T}_{1} \mathrm{a}^{2}, \mathrm{~N}_{0}, \mathrm{M}_{0}\right)$ and two cases of stage II $\left(\mathrm{T}_{2} \mathrm{a}^{1}\right.$, $\mathrm{N}_{0}, \mathrm{M}_{0}$ ), clinical and radiographic examinations made before surgical reintervention, allowed the reinstatement of these three cases in stage $I\left(T_{1}\right.$, $\mathrm{N}_{0}, \mathrm{M}_{0}$ ) but without determining the mitotic index - fig. 3 and 4. There are studies (Ramos et al., 2000) showing that there were no statistically significant differences regarding tumor location, mitotic index, relapse-free interval and survival range.

During laser reintervention the surgigcal steps were conducted in conditions of comfort with wide access, minimum intraoperative bleeding, effective hemostasis - fig. 5 and 6, confirming the advantages of using diode-laser in oral surgery in dogs (De Lorenzi et al., 2015).

After laser reintervention at 24 hours, in all three dogs on the intervention site a slight local redness was observed, without swelling nor bleeding. Palpation of the intervention site also revealed initially (24 hours) a slight local sensitivity which completely disappeared in 48 hours, all dogs resuming to normal eating behavior. There were no grasping and chewing disturbances. Macroscopic operative wound healing occurred in 7-9 days, allowing removal of suture materials- fig 7.

At recheck, performed at 1, 2, 3, 6 and respectively 12 months from the laser reintervention, there were no evidences of tumour recurrence nor metastasis. Comparison of the obtained data with those reported in other studies (Bergman, 2007; Freeman et al., 2013; Nishiya et al., 2016) require as a future need the Smedley et al., 2011 opinion to guide the research for "more rigorous prospective studies, especially to evaluate specific treatment protocols, that would enable a more targeted therapy". 


\section{CONCLUSION}

Diode laser excision of oral malignant melanoma in dogs can be an alternative palliative procedure to invasive surgical resection procedures.

The average of free recurrence and metastasis time after laser surgery has exceeded 360 days in those three cases.

Acknowledgements. This research work was carried out with the support of the project Dezvoltarea infrastructurii de cercetare, educaţie și servicii în domeniile medicinei veterinare și tehnologiilor inovative pentru RO 05, cod SMISCSNR 2669.

\section{REFERENCES}

1. Bergman PJ (2007). Canine oral melanoma. Clin Tech Small Anim Pract , 22(2):55-60.

2. Bostock DE (1979). Prognosis after surgical excision of canine melanomas. Vet Pathol 16: 32-40.

3. Bradley RL, MacEwen EG, Loar AS (1984). Mandibular resection for removal of oral tumors in 30 dogs and 6 cats. J Am Vet Med Assoc 184(4):460-3.

4. Brockley LK, Cooper MA, Bennett PF (2013). Malignant melanoma in 63 dogs (2001-2011): the effect of carboplatin chemotherapy on survival. N Z Vet J 61(1): 25-31.

5. Culp WT, Ehrhart N, Withrow SJ, Rebhun RB, Boston S, Buracco P, Reiter AM, Schallberger SP, Aldridge CF, Kent MS, Mayhew PD, Brown DC (2013). Results of surgical excision and evaluation of factors associated with survival time in dogs with lingual neoplasia: 97 cases (19952008). J Am Vet Med Assoc 242(10): 1392-1397.

6. De Lorenzi D, Bertoncello D, Dentini A (2015). Intraoral diode laser epiglottectomy for treatment of epiglottis chondrosarcoma in a dog. Small Anim Pract 56(11):6758.

7. Esplin DG (2008). Survival of dogs following surgical excision of histologically well-differentiated melanocytic neoplasms of the mucous membranes of the lips and oral cavity. Vet Pathol 45(6):889-96.

8. Felizzola CR, Stopiglia AJ, de Araújo VC, de Araújo NS (2002). Evaluation of a modified hemimandibulectomy for treatment of oral neoplasms in dogs. J Vet Dent 19(3):127-35.

9. Freeman KP, Hahn AK, Harris FD, King KG (2003). Treatment of dogs with oral melanoma by hypofractionated radiation therapy and platinium-based chemotherapy (1987-1997). J vet intern Med 17: 96-101.

10. Gillard M, Cadieu E, De Brito C, Abadie J, Vergier B, Devauchelle P, Degorce F, Dréano S, Primot A, Dorso L, Lagadic M, Galibert F, Hédan B, Galibert MD,André C (2014). Naturally occurring melanomas in dogs as models for non-UV pathways of human melanomas. Pigment Cell Melanoma Res 27(1):90-102.
11. Grosenbaugh DA, Leard AT, Bergman PJ, Klein MK, Meleo K, Susaneck S, Hess PR, Jankowski MK, Jones PD, Leibman NF, Johnson MH, Kurzman ID, Wolchok JD (2011). Safety and efficacy of a xenogeneic DNA vaccine encoding for human tyrosinase as adjunctive treatment for oral malignant melanoma in dogs following surgical excision of the primary tumor. Am J Vet Res 72(12):1631-8.

12. Hahn KA, DeNicola DB, Richardson RC, Hahn EA (1994). Canine oral malignant melanoma: prognostic utility of an alternative staging system. J Small Anim Pract 35:251256.

13. Harvey HJ, MacEwen EG, Braun D, Patnaik AK, Withrow SJ, Jongeward S (1981). Prognostic criteria for dogs with oral melanoma. J Am Vet Med Assoc 178(6):580-2.

14. Kosovsky JK, Matthiesen DT, Marretta SM, Patnaik AK (1991). Results of partial mandibulectomy for the treatment of oral tumors in 142 dogs. Vet Surg 20(6):397401.

15. MacEwen EG, Patnaik AK, Harvey HJ, Hayes AA, Matus R (1986). Canine oral melanoma: comparison of surgery versus surgery plus Corynebacterium parvum. Cancer Invest 4(5):397-402.

16. Modiano JF, Ritt MG, Wojcieszyn J (1999). The molecular basis of canine melanoma: pathogenesis and trends in diagnosis and therapy. J Vet Intern Med 13:163-174.

17. Nishiya, A.T.; Massoco, C.O.; Felizzola, C.R.; Perlmann, E.; Batschinski, K.; Tedardi, M.V.; Garcia, J.S.; Mendonça, P.P.; Teixeira, T.F.; Zaidan Dagli, M.L (2016). Comparative Aspects of Canine Melanoma. Vet Sci 3, 7.

18. Ogilvie GK, Moore AS (1995). Tumors of the oral cavity. In: Managing the veterinary cancer patient (ed Ogilvie GK, Moore AS), Ed. Trenton NJ, Veterinary Learning Systems, 332-336.

19. Ottnod JM, Smedley RC, Walshaw R, Hauptman JG, Kiupel M, (2013). A retrospective analysis of the efficacy of Oncept vaccine for the adjunct treatment of canine oral malignantmelanoma. Vet Comp Oncol 11(3):219-29.

20. Proulx DR, Ruslander DM, Dodge RK, Hauck ML, Williams LE, Horn B, Price GS, Thrall DE (2003). A retrospective analysis of 140 dogs with oral melanoma treated with external beam radiation. Vet Radiol Ultrasound 44(3):3529.

21. Ramos-Vara JA, Beissenherz ME, Miller MA, Johnson GC, Pace LW, Fard A, Kottler SJ (2000). Retrospective study of 338 canine oral melanomas with clinical, histologic and immunohistochemical review of 129 cases. Vet Pathol 37:597-608.

22. Smedley RC, Spangler WL, Esplin DG, Kitchell BE, Bergman PJ, Ho HY, Bergin IL, Kiupel M (2011). Prognostic markers for canine melanocytic neoplasms: a comparative review of the literature and goals for future investigation. Vet Pathol 48(1):54-72.

23. Teixeira TF, Gentile LB, da Silva TC, Mennecier G, Chaible LM, Cogliati B, Roman MA, Gioso MA, Dagli ML (2014). Cell proliferation and expression of connexins differ in melanotic and amelanotic canine oral melanomas. Vet Res Commun 38(1): 29-38.

24. Thomas RC, Fox LE (1998).Tumors of the skin and subcutis. In: Cancer in dogs and cats, medical and surgical 
management(ed Morison Wb). Ed Williams and Wilkins, Baltimore, 499-500.

25. Todoroff RJ, Brodey RS (1979). Oral and pharyngeal neoplasia in the dog: a retrospective survey of 361 cases. J Am Vet Med Assoc 175(6):567-71.

26. Tuohy JL, Selmic LE, Worley DR, Ehrhart NP, Withrow SJ (2014). Outcome following curative-intent surgery for oral melanoma in dogs: 70 cases (1998-2011). J Am Vet Med Assoc 245(11):1266-73.
27. Wallace J, Matthiesen DT, Patnaik AK (1992). Hemimaxillectomy for the treatment of oral tumors in 69 dogs. Vet Surg 21(5):337-41.

28. Williams LE, Packer RA (2003). Association between lymph node size and metastasis in dogs with oral malignant melanoma: 100 cases (1987-2001). J Am Vet Med Assoc 222(9):1234-6. 